\title{
Survey of business excellence by knowledge gathering for industrial Internet-of-Things applications
}

\author{
Jouni K. Tervonen* \\ Kerttu Saalasti Institute, \\ University of Oulu, \\ Pajatie 5, \\ 85500, Nivala, Finland \\ Email: jouni.tervonen@oulu.fi \\ *Corresponding author \\ Johanna Hautamäki
}

Centria University of Applied Sciences,

Talonpojankatu 2,

67100 Kokkola, Finland

E-mail: johanna.hautamaki@centria.fi

\section{Marjo Heikkilä}

Centria University of Applied Sciences,

Vierimaantie 7 ,

84100 Ylivieska, Finland

E-mail: marjo.heikkila@centria.fi

\section{Ville Isoherranen}

Kerttu Saalasti Institute, University of Oulu,

Pajatie 5,

85500, Nivala, Finland

Email: ville.isoherranen@oulu.fi

\begin{abstract}
The Internet-of-Things (IoT) can change not only products but also companies' whole business model. The goal of this article is to inform companies about the creation of business intelligence via utilisation of the industrial loT. This review article assumes that combining business excellence, service design and knowledge gathering via data engineering into cognitive infocommunication (CogInfoCom) opens new possibilities to develop business ideas. These new possibilities are examined through a literature review on deployments of industrial IoT solutions. The survey responds to two research questions: What methods of knowledge gathering and business excellence are used in industrial loT-based product, service and process innovations? How can knowledge gathering, business
\end{abstract}


Jouni K. Tervonen et al.

excellence and CogInfoCom methods be utilised to create added value in industrial IoT solutions? This survey reveals the richness and delicacy of these exploitation opportunities.

Keywords: business excellence, business intelligence, business process management, case studies in industry, cognitive data communication, computational intelligence, data engineering, data mining, development, enterprise modelling and management, industrial Internet-of-Things, knowledge-intensive service design, literature review, management, operational maturity review

Reference to this paper should be made as follows: Tervonen, J.K., Hautamäki, J., Heikkilä, M. and Isoherranen, V., (2018) 'Survey of business excellence knowledge gathering for industrial Internet-of-Things applications', Int. J. of Management and Enterprise Development, Vol. X, No. Y, xxxx

Biographical notes: Dr Jouni K. Tervonen has been a researcher with Helsinki University of Technology and senior specialist with Nokia Networks, Finland. From 2004 to 2018, he worked for the Kerttu Saalasti Institute, University of Oulu, Nivala, Finland. His current research interests include industry-driven solutions utilising the Internet-of-Things, including data fusion, the data analysis of sensor data, and wireless sensor and actuator networks.

Johanna Hautamäki received a MA in industrial design from the multidisciplinary Design, Media and Markets programme at the University of Lapland, Rovaniemi, Finland, in 2015. She has worked as an independent designer since 2002 and as project manager and service designer (2014-) and project planner in general research and development (R\&D) at Centria University of Applied Sciences (2012-2013). Her research in the on-going project AppSim - Creating competence through applied simulation pedagogy, digitality and service design - focuses on developing new operational models and competences for co-operation in education, working life and $R \& D$. The development process combines service design with anticipation and multidisciplinary applied simulation pedagogy. Since 2014, she has developed a service prototyping and development environment and methods at Centria. Her current research interest is multidisciplinary work in different fields through service design and anticipation.

Marjo Heikkilä is research and development manager at Centria University of Applied Sciences. She has 20 years of experience in various research and development projects on wireless communication systems and applications. Her research interests include the industrial Internet, 5G network testing and critical operations over $5 \mathrm{G}$ networks.

Dr Ville Isoherranen received his MSc (Eng.) in 2002 and DSc (Tech.) in 2012. He has served as director of the international research institute Kerttu Saalasti Institute (KSI), University of Oulu. He has international and cross-functional industrial management experience in various positions in sales and marketing and supply chain management (Nokia Corporation, 2002-2014) and management consulting (ABB Group, 2012-2014). His research interests are strategic management, operational excellence and customer-focused enterprises.

This paper is a revised and expanded version of a paper entitled 'A review of the cognitive capabilities and data analysis issues of the future Industrial Internet-of-Things' presented at IEEE International Conference on Cognitive 
Survey of business excellence

Infocommunications, Győr, Hungary, 19-21 October 2015.

\section{Introduction}

The Industrial Internet can change not only products but also firms' whole business model. Several publications have offered definitions of the Internet-of-Things (IoT). For example, Atzori et al. (2010) stated the basic IoT concept the pervasive presence of a variety of Internet-connected objects (e.g. sensors, actuators, mobiles phones and radiofrequency identification [RFID] tags). Originating from rather simple RFID solutions, the IoT has become very rich, involving different types of objects and heterogeneous wired and wireless networks, which can all interact among themselves and with external systems. Remote monitoring and preventive maintenance can be enabled by adding sensors, data gathering and analytics to products. When continuous, real-time visibility is achieved in products, it enables offering broader services. The company can now offer products as services or after-sales services. Several good articles on the IoT (e.g. Atzori et al., 2010; Tsai et al., 2014b; Xu et al., 2014) have discussed the opportunities, current state, open issues and challenges in the IoT or the industrial IoT. Open, technical and standardisation-related challenges need to be solved to fully realise the possibilities of the industrial IoT. Moreover, security- and privacy-related issues can be described as threats for successful utilisation of IoT. For instance, Atzori et al. (2010) pointed out that the widespread adoption of the IoT makes everyday objects far more severe security and privacy risks than the Internet today. Similarly, Tsai et al. (2014b) and Xu et al. (2014) highlighted security and privacy as future challenges of IoT. The main assumption in this review article is that combining the aspects of business excellence, service design and data engineering into cognitive infocommunication (CogInfoCom) creates new possibilities to develop business ideas.

In section 2, we discuss the research scope and methodologies used and review present work related to business excellence and the knowledge and data engineering used in the IoT. For data engineering, we find uses cases of computational intelligence (CI) and data mining methods in IoT applications in the IoT domain and consider them from the perspectives of business maturity in section 3 and CogInfoCom in section 4 . Section 5 gives examples of how service design based on data analysis can enhance CogInfoCominspired solutions design and implementation. In section 6, future trends and challenges are projected based on the literature review and our experiences in several related research projects. Finally, all the relevant findings are discussed, and conclusions are drawn in section 7 .

\section{Research frame and related work}

\section{$2.1 \quad$ Research background and motivations}

We are investigating, utilising and further developing knowledge and data engineering methods as part of the industrial IoT in the on-going research project Industrial Internet as a Business Enabler - IIBE. The aim of this project is to strengthen companies' ability to benefit from the industrial Internet. In addition, the project also aims to identify networking-related threats and manage the risks of the industrial Internet, in which 
Jouni K. Tervonen et al.

industry uses sensor and information networks to improve business productivity and generate new business. Analysis of collected sensor data enables generating new business models and combining production processes. Another project aim thus is to combine information and communications technology expertise with industrial automation systems expertise. The project identifies the key elements of the industrial Internet and automation systems to create reliable solutions for data transmission from automation systems. The project objective is to enable industrial process monitoring, control, reliable connections among companies' remote sites and the connection of critical systems using reliable, energy-efficient wireless sensor networks. The key goal of the project is to provide information about how industrial companies can take advantage of the Industrial Internet. The project thus will support utilisation of wireless sensor networks, analysis of collected sensor data on companies' business development and creation of new business cases. The project will facilitate the service design of the selected concepts and the demonstration of use cases.

\section{$2.2 \quad$ Research questions, scope and methodology}

The goal of this article, as well as our research project, is to provide companies with information on the creation of business intelligence via utilisation of the industrial IoT. The main novelty of this review article compared to our earlier survey (Tervonen et al., 2015 ) is the analysis of business excellence in enabling new product, service and process innovations. Given that our previous review concentrated on data gathering and analysis and aspects of CogInfoCom methods, this article responds to two research questions:

Q1: What methods of knowledge gathering and business excellence are used in industrial IoT-based product, service and process innovations?

Q2: How can knowledge gathering, business excellence and CogInfoCom methods be utilised in the creation of added value in industrial IoT solutions?

The scope of this article is a literature review of deployments of industrial IoT solutions. Given that the industrial Internet is our key research theme, and business excellence is most clearly involved in the industry domain, this study concentrates on IoT applications in the industry domain. Another inclusion criterion in this survey is deployment or test case implementation, which enables estimating the level of achieved or potential business excellence and better evaluating the CogInfoCom aspects.

The research philosophy and methodologies of our selections are presented using the framework described by Creswell and Plano Clark (2011). Of the four possible research worldviews, the pragmatist worldview is the most suitable for our problem-centred, practice-oriented approach. The main methodology is a literature review, so the theoretical lenses and frames are extracted from the selected literature. Using the literature as the main source requires applying qualitative or mixed methods. In this mixed methods research, the main analyses are qualitative, while a quantitative method is used to evaluate business maturity levels.

\subsection{Related work on knowledge gathering}

Several good review articles on the IoT (e.g. Tsai et al., 2014b; Xu et al., 2014) have discussed the importance of artificial intelligence and knowledge gathering as one open issue in IoT solutions is knowledge gathering from data sensing. Data mining is an important part of the adapted knowledge discovery in databases (KDD) model originally 


\section{Survey of business excellence}

presented by Fayyad et al. (1996). This KDD model used is shown in Figure 1. As our perspective for this study includes the transformation of companies, one possibility for analysis is to evaluate companies' capability to exploit data and digital engineering tools.

We are interested in expanding the traditional KDD model to analyse methods to utilise data engineering in creating business excellence. This study focuses on the changes in practices and processes required to gain business excellence utilising and based on knowledge via KDD (the upper part of Figure 1).

Another aspect of business excellence is process excellence, which is enabled and ensured via proper business-process monitoring. Based on research on essential businessprocess-monitoring systems, Domínguez et al. (2014) proposed a novel development scheme with three dimensions handled simultaneously: structure (i.e. objects), behaviour (i.e. states, state changes and events) and guidance (i.e. protocols, processes and protocol performances). The proposed concept was demonstrated via implementation based in

Figure 1 Model of knowledge gathering

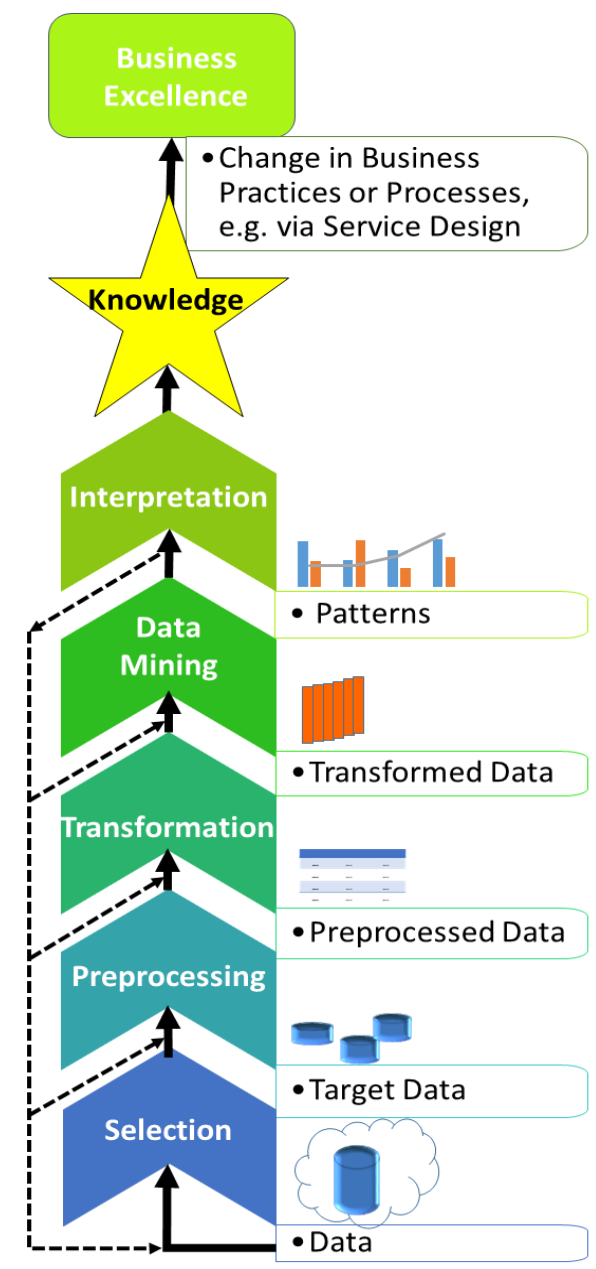

Source: Fayyad et al. (1996); Tsai et al. (2014a) 
Jouni K. Tervonen et al.

unified modelling language (UML).

The $\mathrm{CI}$ and the data mining perspectives can both address the data engineering methods used in IoT solutions. CI usage in the IoT or, more specifically, in wireless sensor networks (WSN) is more deeply analysed by Kulkarni et al. (2011). This study showed that several CI paradigms have been used to solve various classes of challenges in the design and deployment and the operational phases of WSN solutions. The comprehensive analysis detailed the research activities involving each combination of different CI paradigms and WSN challenges. The analysis included a general evaluation of which CI algorithms are appropriate and suitable for each WSN issue. One overall finding was the lack of experiments with either testbed cases or deployments. In this paper, we select four real-world cases, which are further analysed and discussed in section 3 .

A recent IoT data mining survey (Tsai et al., 2014a) specified a data mining classification paradigm and gave IoT-related examples for each data mining classification. They classified the methods as clustering, classification, frequent pattern mining or hybrid. Hybrid method defined as utilising the basic methods in phases. To conduct an analysis in our survey, we select real-world examples related to industrial applications. From the perspective of data, there is a need to cope with large-scale data entering dynamically and quickly from different types of sources. The heterogeneous sensors and devices connected to the IoT typically conduct actions in their own ways. Knowledge sharing among applications, services and systems, therefore, is much more important than in traditional homogeneous systems. From the infrastructure perspective, the heterogeneous and decentralised nature of the IoT is found by Tsai et al. (2014a) to strongly influence the usage and development of mining algorithms, which prompts reconsideration of the appropriate decentralised mining technologies for the IoT. One attempt to provide different data mining models for IoT solutions using either decentralised or centralised approaches was provided by Bin et al. (2010). Cantoni et al. (2006) analysed the challenges in distributed sensor networks and concluded that pattern recognition, data mining and data fusion are key issues in elaborating reactive decisions. Moreover, they stated that complex pattern recognition and data mining can be effectively performed when relying on a mainly centralised approach in which the computational power is not constrained (Cantoni et al., 2006).

Tsai et al. (2014b) discussed examples in which both CI and data mining are essential in IoT solutions. They concluded that the inclusion of intelligence and data analysis requires rethinking the architectural choices of IoT solutions. In our earlier work (Tervonen et al., 2014), we also noted the importance of adaptive architecture and discussed some of the CogInfoCom aspects of IoT applications.

\section{$2.4 \quad$ Related work on cognitive infocommunication}

CogInfoCom issues (Baranyi and Csapó, 2012; Sallai, 2012) are increasingly considered in the development of IoT solutions. Objects cooperate with their neighbours to achieve common goals. In intra-cognitive communication, two cognitive beings have the same cognitive capabilities. In inter-cognitive communication, natural and artificial cognitive systems have different cognitive capabilities but should be able to work together efficiently; take, for instance, a driver and a car as part of an intelligent traffic system (ITS). Thus, inter-cognitive communication is becoming a prerequisite, for instance, in autonomous vehicles (Tien, 2017).

In our previous survey (Tervonen et al., 2015), we studied and discussed the role and 


\section{Survey of business excellence}

impact of data engineering and CogInfoCom issues in the current and future development of the industrial IoT. In this extension survey, we focus on how data engineering and the CogInfoCom approach can and should be utilised in the creation of business excellence. We evaluate different solutions based on the classification of the IoT application domains of industry, environment and society (Guillemin et al., 2009; Perera et al., 2014).

A recent study (Xu et al., 2014) reviewed industry-related research on the IoT, discussed the key enabling technologies and identified research challenges and trends. Two of the five research trends identified in the study are of particular interest to our research theme of knowledge and data engineering in the industrial IoT:

(1) Employment of artificial intelligence techniques to create smart objects

(2) Integration of social networks with IoT solutions

The former is related to our goal to create new business opportunities and novel practices and processes via knowledge gathering. Moreover, the inclusion of social networking emphasises the need for a CogInfoCom approach to address the inter-cognitive communication between artificial objects and humans utilising social networks, in addition to the generally intra-cognitive communication needs of the things in basic IoT solutions. The inclusion of human and social aspects is important. The concept of the social IoT was introduced and discussed by Atzori et al. (2012). As the social IoT becomes formalised, it will suffer similar issues as other IoT systems. For instance, without affective trust management, attacks and malfunctions will outweigh any benefits of the IoT (Nitti et al., 2014). In addition to stressing the importance of trust issues, Nitti et al. (2014) proposed two models for trustworthiness management in the social IoT.

\subsection{Related work about business excellence}

One element in the creation of business excellence is how IoT solutions (i.e. smart and connected products) will affect competition and companies themselves, as discussed by Porter and Heppelmann $(2014,2015)$. The IoT era requires that companies gain and maintain competitive advantages by differentiating themselves. Simultaneously, IoT products are defining a new de-facto standard that dramatically increases the target level of best practices, particularly for operational effectiveness and maturity (Porter and Heppelmann, 2014). Accordingly, data analytics capabilities of firms will become essential and even reshape manufacturing companies to resemble software houses (Porter and Heppelmann, 2015).

Excellence of operations will support all selected business strategies. Companies need process excellence to be able to apply data-driven operations. Operational excellence can be defined as the alignment of all of firms' efforts, data, decisions and processes. These all should also be customer oriented to achieve excellence (Boothe and Lindberg, 2014; Isoherranen and Kess, 2011). The maturity model evaluation indicates the current level of excellence, providing a baseline for development activities and learning paths (Isoherranen et al., 2016).

In our study of business excellence, we use a maturity model as a review tool. In sections 3 and 4, we utilise a recently published, four-level maturity model for digital engineering in the IoT era (Goto et al., 2016):

- Level 0: As Is: Manufacturing companies do not utilise the possibilities of digitalisation.

- Level 1: Improvement: Digital engineering is used for the aim to improve and introduce new products.

- Level 2: Reforming: IoT technologies are included to reform and achieve total optimisation of the whole product life cycle. 
Jouni K. Tervonen et al.

- Level 3: Transformation: Real-time collection and analysis of digital data are introduced, enabling transformations not conceivable in the past.

These are the main elements of the maturity model levels. For complete definitions, see Goto et al. (2016).

\section{Experimental cases utilising computational intelligence}

\subsection{Approach}

As the analysis by Kulkarni et al. (2011) shows, numerous research studies have demonstrated that CI plays an important role in IoT solutions. However, the majority of these studies were based on simulations. For our research purposes, we select only industry-related deployments or test case solutions, allowing us to estimate business excellence and to consider the CogInfoCom issues in these cases. To estimate business excellence, we use the maturity model recently proposed by Goto et al. (2016).

\subsection{Cases}

The involvement of CI begins during the design and deployment phase of industrial IoT applications. Take, for instance, the WSN design case reported by Carballido et al. (2007). The task to solve is the design of the type, amount and location of nodes for deployment in an industrial processing plant. The computational method used is an evolutionary or genetic algorithm, the graph-based genetic algorithm for sensor network design (CGD-GA). The CI method is used for improvements in the design and deployment phase of the IoT solution, so we place this case at maturity level 1.

Another sensor network design and deployment example, also at level 1 maturity, involves an ITS as, according to Perera et al. (2014), transport solutions belong to the industry domain. Hu et al. (2006) presented the particle-swarm-optimisation network design for urban traffic-surveillance systems (PSO-UTSS). The PSO-UTSS method belongs to the swarm intelligence class and is used to plan the topology and location of surveillance cameras.

Reinforcement learning or, more specifically, Q-learning is used to plan energyefficient routing of a WSN application with multiple sinks. Förster and Murphy (2011) introduced the multicast routing protocol, feedback routing to multiple sinks (FROMS), based on theoretical analysis and experimental results complementing earlier simulation results (Förster and Murphy, 2007). The experimental results of FROMS are exploited by a testbed with 10-15 nodes. Thus, this solution does not clearly belong to any specific IoT domain. However, the requirement analysis of FROMS development is guided by potential environmental monitoring and military applications. In our opinion, this routing protocol is also well suited for use in industry, for example, in process automation cases with multiple sinks. The overall maturity level of applications based on FROMS can be higher, but the core of FROMS (i.e. improved routing) is judged to at level 1.

The energy efficiency of WSNs is the key IoT challenge in a flooding-based data aggregation method intended to reduce power consumption in WSNs (Lazzerini et al., 2006). The data aggregation method, realised via fuzzy logic, was demonstrated by monitoring the maximum temperature in a $200 \mathrm{~m}^{2}$ flat with 12 sensor motes. Although Perera et al. (2014) placed both smart building and home applications within the domain of society, building and home automation straddles the border between the society and industry domains. Additionally, this data aggregation model is undoubtedly feasible in cases more clearly situated in the industrial domain. The data aggregation itself is 


\section{Survey of business excellence}

considered to be at level 1 maturity due to improvement of WSN performance, but the total value of the whole solution could result in a higher maturity level.

\subsection{Summary}

As these examples and the summary in Table 1 illustrate, several CI methods have been used in WSN-based industrial IoT experiments. Table 1 also includes our evaluation of the methods' maturity level based on the model proposed by Goto et al. (2016). The operational WSN efficiency-related issues of routing and scheduling are distributed and dynamic problems for which reinforcement learning is found to be the most suitable CI method. The design and deployment of sensors is usually a centralised problem for which the neural network, evolutionary algorithm and swarm intelligence methods present wellsuited solutions (Kulkarni et al., 2011). These experimental cases have the common goal to maximise the energy efficiency of WSNs, regardless of whether the CI method is utilised in design and deployment, routing and scheduling or data aggregation. From the CogInfoCom perspective, these methods are characterised by minimising or optimising the intra-cognitive communication between objects (i.e. non-human artefacts). The IoT is generally believed to still be in its infancy ( $\mathrm{Li}$ et al., 2015; Xu et al., 2014), so the CI solutions utilised in future IoT solutions will also need to account for human involvement and, thus, all the aspects of inter-cognitive communication.

Table 1 Summary of computational intelligence experimental cases

\begin{tabular}{|c|c|c|c|c|c|}
\hline Example case & CI method & IoT challenge & $\begin{array}{c}\text { IoT } \\
\text { Domain }\end{array}$ & $\begin{array}{l}\text { Maturity lev } \\
\text { in model of } \\
\text { Goto et al. } \\
\text { (2016) }\end{array}$ & $\begin{array}{l}\text { CogInfoCom } \\
\text { remark }\end{array}$ \\
\hline $\begin{array}{l}\text { CGD-GA } \\
\text { (Carballido et } \\
\text { al., 2007) }\end{array}$ & $\begin{array}{l}\text { Evolutionary } \\
\text { algorithm }\end{array}$ & $\begin{array}{l}\text { Design and } \\
\text { deployment of } \\
\text { WSN parts (type, } \\
\text { amount and } \\
\text { location of nodes) }\end{array}$ & $\begin{array}{l}\text { Industry: } \\
\text { process } \\
\text { automation }\end{array}$ & Level 1 & $\begin{array}{l}\text { Intra-cognitive } \\
\text { communication } \\
\text { between objects } \\
\text { (sensor nodes) }\end{array}$ \\
\hline $\begin{array}{l}\text { PSO-UTSS } \\
\text { (Hu et al., } \\
2006)\end{array}$ & $\begin{array}{l}\text { Swarm } \\
\text { intelligence }\end{array}$ & $\begin{array}{l}\text { Design and } \\
\text { deployment of } \\
\text { sensor network } \\
\text { (topology planning } \\
\text { for cameras as } \\
\text { sensors) }\end{array}$ & $\begin{array}{l}\text { Industry: } \\
\text { ITS }\end{array}$ & Level 1 & $\begin{array}{l}\text { Intra-cognitive } \\
\text { communication } \\
\text { between objects } \\
\text { (sensor nodes) }\end{array}$ \\
\hline $\begin{array}{l}\text { FROMS } \\
\text { (Förster and } \\
\text { Murphy, 2007; } \\
\text { Förster and } \\
\text { Murphy, 2011), }\end{array}$ & $\begin{array}{l}\text { Reinforcement } \\
\text { learning }\end{array}$ & $\begin{array}{l}\text { Q-learning for the } \\
\text { energy efficient } \\
\text { routing of WSNs }\end{array}$ & $\begin{array}{l}\text { Not } \\
\text { specified } \\
\text { (testbed) }\end{array}$ & Level 1 & $\begin{array}{l}\text { Intra-cognitive } \\
\text { communication } \\
\text { between objects } \\
\text { (sensor nodes) }\end{array}$ \\
\hline $\begin{array}{l}\text { Data } \\
\text { aggregation } \\
\text { (Lazzerini et } \\
\text { al., 2006) }\end{array}$ & Fuzzy logic & $\begin{array}{l}\text { Flooding-based } \\
\text { data aggregation } \\
\text { to reduce power } \\
\text { consumption of } \\
\text { WSNs }\end{array}$ & $\begin{array}{l}\text { Society and } \\
\text { industry }\end{array}$ & Level 1 & $\begin{array}{l}\text { Intra-cognitive } \\
\text { communication } \\
\text { between objects } \\
\text { (sensor nodes) }\end{array}$ \\
\hline \multicolumn{6}{|c|}{$\begin{array}{l}\text { The IoT domain of reinforcement learning is not specified, but the design } \\
\text { is inspired by the environment domain and is well suited for the industry } \\
\text { domain (e.g. process automation). } \\
\text { The maturity levels are: Level 0: As Is; Level 1: Improvement; } \\
\text { Level 2: Reforming; and Level 3: Transformation. }\end{array}$} \\
\hline
\end{tabular}


Jouni K. Tervonen et al.

\section{Experimental cases utilising data mining}

\subsection{Approach}

Drawing on a data mining survey (Tsai et al., 2014a), we adopt the data mining method classifications of clustering, classification, frequent pattern mining and hybrid and discuss example experimental cases of these classifications. As in Section 3, our analysis is aimed at evaluating business maturity with the maturity model of Goto et al. (2016).

\subsection{Clustering cases}

Tsai et al. (2014a) provided some examples of the use of the clustering method in the environment and society domains, which are outside the scope of this survey. They also examined how to utilise the clustering method in the network performance of energyefficient routing in WSNs in several simulation-based cases (e.g. Ghiasi et al., 2002; Heinzelman et al., 2002; Younis and Fahmy, 2004). Routing performance improvements belong to business maturity level 1. We are interested in deployments, and the CogInfoCom-related aspects are very similar to those considered in the previous section, so these cases are not given detailed consideration.

\subsection{Classification cases}

Traffic forecast services were studied and deployed by Horvitz et al. (2005). Classification was used in the development of forecast models for traffic flow and congestion. The basic functionality of the service is to monitor traffic patterns and use the probabilistic method to predict congestion and flow. As well as the traffic measurements, the system uses intra-cognitive communication to gain additional information about weather, time, date and major events, such as sports. The system also has two interfaces for inter-cognitive communication with humans. This solution is evaluated at maturity level 2 as it clearly includes IoT solution with connected products, people and IT infrastructure systems. The desktop-based configuration tool allows users to design routespecific alerts. The mobile smartphone application shows current congestion at known bottlenecks and estimates when congestion will clear or when an open route will become congested. In addition, the reliability of the forecast and the potential for surprises (i.e. anomalies from typical traffic patterns) are visualised.

Another driver guidance tool for avoiding congestion that uses location services was introduced by Perera and Dias (2011). Like the previous case example, this solution is judged to be at level 2, reforming maturity. The system is comprised of mobile devices, social network servers, system web servers, central processors, data processing nodes, vehicle tracking servers and external servers. The vehicle tracking along the route utilises the global positioning system (GPS). The solution has an interface for social networks, such as Facebook and Twitter. When connected to social networks, mobile phones in this system use textual, graphical and audio outputs. The system is based on a decision-treebased classification model that tracks the results for given conditions and later uses them to build more accurate predictions.

A WSN-based IoT solution for an intelligent parking-monitoring application was developed by Sudhaakar et al. (2009). It uses a pair of passive infrared sensors to recognise cars at the gates of a parking lot. The classification method is used to distinguish car entry from car exit. Intra-cognitive communication takes place between the sensor nodes and the server, while inter-cognitive communication occurs between the server and the commuter via on-demand, short-message-service notifications. Due to the 


\section{Survey of business excellence}

inclusion of IoT solutions with connected products, people and IT infrastructures, this solution is evaluated at maturity level 2 .

\subsection{Frequent pattern mining and hybrid cases}

Temporal management of large-scale RFID applications (TMS-RFID) was introduced by Li et al. (2011). Many RFID applications are time sensitive, so the time-to-live concept was introduced to represent the length of time an RFID event can legally live in an RFID data management system. This system includes three databases: a central database, a query database and an event-type database. The frequent pattern method was used in the demonstration of TMS-RFID's effectiveness at extracting complex event patterns. We evaluate TMS-RFID, as an improvement of an IoT solution, at maturity level 1.

Somasundaram et al. (2010) presented an intelligent RFID system for monitoring customer behaviour in stores to recommend items to customers, thereby increasing customer satisfaction. This solution includes an understanding of customer value beyond the functional value of the connected product, so we place this solution at level 3, enabling previously impossible transformations of customer satisfaction. The system consists of three components: RFID-tagged products, an RFID-reader-enabled mobile device and a backend enterprise system. Intra-cognitive communication occurs between the product and the backend via mobile devices, while an inter-cognitive communication link exists between the backend system and the customer. The frequent pattern method

Table 2 Summary of data mining cases in the industry domain

\begin{tabular}{|c|c|c|c|c|c|}
\hline Example case & $\begin{array}{l}\text { Data mining } \\
\text { method }\end{array}$ & IoT challenge & IoT domain & $\begin{array}{l}\text { Maturity level } \\
\text { in model of } \\
\text { Goto et al. } \\
\text { (2016) }\end{array}$ & $\begin{array}{c}\text { CogInfoCor } \\
\text { remark }\end{array}$ \\
\hline $\begin{array}{l}\text { Routing } \\
\text { algorithms }\end{array}$ & Clustering & $\begin{array}{l}\text { Efficient } \\
\text { routing } \\
\text { protocol for } \\
\text { WSNs }\end{array}$ & $\begin{array}{l}\text { Industry, } \\
\text { environment, } \\
\text { society }\end{array}$ & Level 1 & $\begin{array}{l}\text { Intra-cognitive } \\
\text { communication } \\
\text { between objects } \\
\text { (sensor nodes) }\end{array}$ \\
\hline $\begin{array}{l}\text { Traffic forecast } \\
\text { (Horvitz et al., } \\
\text { 2005) }\end{array}$ & Classification & $\begin{array}{l}\text { ITS traffic } \\
\text { forecast for } \\
\text { congestion } \\
\text { avoidance }\end{array}$ & $\begin{array}{l}\text { Industry: } \\
\text { ITS }\end{array}$ & Level 2 & $\begin{array}{l}\text { Several intra- } \\
\text { cognitive and } \\
\text { two inter- } \\
\text { cognitive } \\
\text { communication } \\
\text { links }\end{array}$ \\
\hline $\begin{array}{l}\text { Driver guidance } \\
\text { (Perera and } \\
\text { Dias, 2011) }\end{array}$ & Classification & $\begin{array}{l}\text { ITS intelligent } \\
\text { driver- } \\
\text { guidance tool } \\
\text { for congestion } \\
\text { avoidance }\end{array}$ & $\begin{array}{l}\text { Industry: } \\
\text { ITS }\end{array}$ & Level 2 & $\begin{array}{l}\text { Intra- and inter- } \\
\text { cognitive } \\
\text { communication }\end{array}$ \\
\hline $\begin{array}{l}\text { Gate monitoring } \\
\text { (Sudhaakar et al., } \\
\text { 2009) }\end{array}$ & Classification & $\begin{array}{l}\text { WSN-based } \\
\text { car-parking } \\
\text { aid }\end{array}$ & $\begin{array}{l}\text { Industry: } \\
\text { logistics } \\
\text { and } \\
\text { transport }\end{array}$ & Level 2 & $\begin{array}{l}\text { Intra- and inter- } \\
\text { cognitive } \\
\text { communication }\end{array}$ \\
\hline $\begin{array}{l}\text { TMS-RFID } \\
\text { (Li et al., 2011) }\end{array}$ & $\begin{array}{l}\text { Frequent } \\
\text { pattern } \\
\text { mining }\end{array}$ & $\begin{array}{l}\text { Temporal } \\
\text { management } \\
\text { of large-scale } \\
\text { RFID } \\
\text { applications }\end{array}$ & $\begin{array}{l}\text { Industry, } \\
\text { environment, } \\
\text { society }\end{array}$ & Level 1 & $\begin{array}{l}\text { Intra-cognitive } \\
\text { communication } \\
\text { between objects } \\
\text { (readers, tags } \\
\text { and databases) }\end{array}$ \\
\hline $\begin{array}{l}\text { Intelligent RFID } \\
\text { (Somasundaram } \\
\text { et al., 2010) }\end{array}$ & $\begin{array}{l}\text { Frequent } \\
\text { pattern } \\
\text { mining }\end{array}$ & $\begin{array}{l}\text { Customer } \\
\text { satisfaction } \\
\text { and guidance } \\
\text { in shops }\end{array}$ & $\begin{array}{l}\text { Industry: } \\
\text { logistics }\end{array}$ & Level 3 & $\begin{array}{l}\text { Intra- and inter- } \\
\text { cognitive } \\
\text { communication }\end{array}$ \\
\hline
\end{tabular}

Notes: $\quad$ There are several examples of routing algorithms for energy-efficient protocols for WSNs (Ghiasi et al., 2002; Heinzelman et al., 2002; Younis and Fahmy, 2004).

Maturity levels are: Level 0: As is; Level 1: Improvement;

Level 2: Reforming; Level 3: Transformation. 
Jouni K. Tervonen et al.

(i.e. the association rule mining technique) is essential in the backend system. The backend system of enterprise is comprised of:

(1) Intelligent systems applying rule- and case-based reasoning to identify preferred products

(2) A database to store users' profiles and previous purchase history for search and processing

The hybrid data mining analysis and applications developed by Tsai et al. (2014a) concentrate on the society domain (i.e. inhabitant-action prediction in smart homes). Nevertheless, action-prediction methods, such as those demonstrated on the same smarthome testbed (Rashidi and Cook, 2010; Rashidi et al., 2011), have potential for use in customer-activity prediction in industry.

\subsection{Summary}

Table 2 presents a summary of these cases of the experimental use of different data mining methods in the industrial IoT, as well as the business excellence estimated using the maturity model of Goto et al. (2016). These experiments demonstrate the usefulness and potential of various data mining methods exploitable in the purely industrial IoT and more widely in several IoT domains. These experiments can be considered to be showcase examples of human decision making augmented by the artificial cognitive capability of IoT applications. Both intra-cognitive communication among several heterogeneous objects and inter-cognitive communication between humans and objects define future requirements. Inter-cognitive communication in ITS applications deserves further study as highly cognitive humans should experience messages from traffic-aid systems as easy and simple to ensure their undisturbed concentration on traffic itself.

\section{Service design approach and cases}

The cases presented here are examples of how understanding value creation can open new possibilities to develop business excellence with IoT in the industry domain. Understanding stakeholders' interactions and the value created in service processes is essential (Kimbell, 2010). New service and business innovations, as well as technology, alter organisational routines and interactions to provide new value propositions and solutions to customers (Janssen and den Hertog, 2016).

In the traditional industrial mind-set, the concept of value production is embedded in material value and produced goods. New understandings of value emphasise the connections between the product, service and customer and sees value as co-created in interactions with the customer. The understanding of value creation has shifted from seeing value as embedded in tangible goods to co-created by actors in a service process (Sangiorgi, 2012).

\subsection{Kone Case}

Paola Bello (2017) analysed the case study of Kone Corporation, which shifted its operation model from product-focused engineering to a customer-driven, user-driven orientation. Organisational-level development requires actions on both the strategic level and the services and products level. In this transformation process, it is important to understand the organisation's value proposition for customers and product users. Part of this understanding is that the service is provided for the customer and is not an activity done with the machinery provided by Kone. In the new model described in this case, user and customer needs are met through a combination of life-cycle services and products, 


\section{Survey of business excellence}

and the value production is based on a holistic, long-term plan for the solutions portfolio. Kone has succeeded in service design by working with it on many levels of the organisation, from the strategic planning level to the customer and user levels. Implementation included planning through pilot tests and developing through experimentation.

Building service models on experienced engineering products generates more value from customer- and user-centric solutions than mere products. In this case, the shift is happening, but in big organisations such as Kone, transformation takes time. A clearly visualised plan, along with results, is a strong foundation for long-term impacts.

\subsection{TomTom Case}

TomTom (TomTom International BV, 2016a) is developing a new city service based on a database of 14 trillion measurements collected over eight years by more than 450 million devices globally. The database is growing daily with more than 10 billion new GPS measurements on 6 million trips covering 190 million kilometres. The new service combines collected and live data, enabling it to more accurately anticipate solutions for users. The data streams in this case are bidirectional as data are both collected and provided. The combination of the database with live data provides unique possibilities for anticipating future and developing services. Due to increasing mobility, cities and drivers face congestion challenges, and it is vital to solve issues, such as optimising road networks and fuel consumption to control traffic and $\mathrm{CO}_{2}$ emissions (TomTom International BV, 2016b).

As this case shows, the value to the customer is not the collected data but the services developed based on it through understanding the customer and operational environment. TomTom Innovation (TomTom International BV, 2016b) is focusing on the future possibilities of transportation, cars, roads and technology. The ever-increasing data stream in smart cities is a growing challenge. The number of smart components, such as IoT sensors and devices, is rising as smart cities are becoming ecosystems in which transportation and energy are fundamental stakeholders (Schleicher et al., 2016). If mobile IoT devices, such as navigators in the TomTom case, are seen as more than data sources and command receivers in future, they could enable new business and service models.

\subsection{Summary}

Service design methods with co-creation and visualisation provide tools to bridge the gap between produced data and users by understanding value production and user orientation. Through co-creation with deep understanding of the user and the use context, we can create new value with gathered data to develop new service and business models based on new technological possibilities.

Customers increasingly need more holistic service solutions instead of products and services that provide partial solutions (Ojasalo, 2017). Service design provides concrete tools for bringing customer and user perspectives and experiences into industrial processes. These tools help develop big data into new services and business models, which produce value for customers and users.

We can create new perspectives on technological possibilities with a holistic approach by bringing service design into the process. The role of service design related to the IoT and data mining can be seen from two different perspectives:

1. Existing data or IoT activity: In the knowledge phase (Figure 1), new business models or services are built, and existing ones are developed with service design. 
Jouni K. Tervonen et al.

2. Anticipatory and interactive process incorporating service design from the beginning (Figure 2): Value creation and user and use-context understanding are included the process when first planning data mining or IoT solutions.

\section{Future trends and challenges}

\subsection{Technical trends and open issues}

Knowledge discovery in databases, whether through data mining and other CI, will certainly be a key driver in reshaping business models and generating new business opportunities in future IoT applications. These data analysis methods enable the creation of semiautomatic systems capable of 'self-configuration, self-optimisation, selfprotection, and self-healing' (Xu et al., 2014). The data-analysis-enhanced performance of devices gives them basic autonomous or cognitive capabilities. The combination of artificial cognitive objects and human capabilities will lead to the effective augmentation of humans. However, the creation of artificial cognitive systems will require advanced intelligent techniques. In other words, data mining techniques need to be redesigned to meet the need of the future IoT, including both cloud computing and social networking.

Until recently, research on the IoT has focused on architectural choices and key technologies to guarantee reliability and efficiency amid well-known WSN constraints. WSN design and deployment can be solved with centralised CI methods, while operational issues of routing and scheduling seem to require distributed CI methods. From the CogInfoCom perspective, early CI implementations are focused on intracognitive communication between sometimes heterogeneous sensors and actuator objects.

The combination of data mining technologies and iterative learning methods is one possible way to enhance IoT as the system may learn incrementally and even interact with people. The data mining related examples in ITS and logistics give a glimpse of the potential of humans augmented with the artificial cognitive capabilities of the IoT system. In the future, with the large number of things connected to the Internet, massive amounts of data will be generated. Analysing and mining huge amounts of data to get valuable information requires strong big-data analytics skills, which might be challenging for many end users 
Survey of business excellence

Figure 2 Outline of parallel knowledge discovery and service design

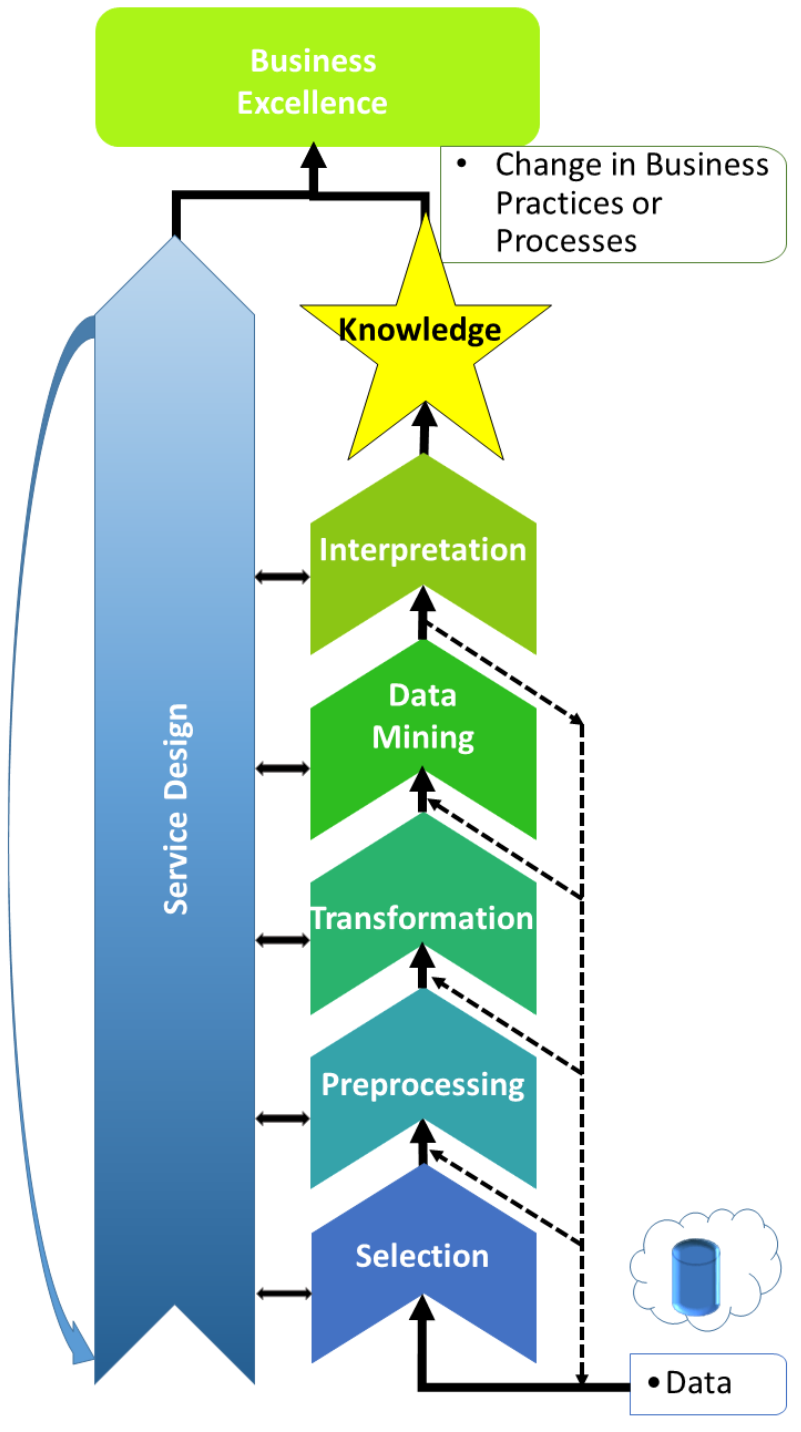

\subsection{Standardisation issues}

An open issue in the IoT today is that standardisations of the IoT are not integrated into a comprehensive framework (Atzori et al., 2010). The rapid growth of the IoT makes standardisation difficult. Many countries and organisations are interested in developing various IoT standards as it could bring tremendous economic benefits in the future. Various standards used on the IoT (e.g. security, communication and identification standards) might be the key enablers of the spread of IoT technologies; therefore, they need to be designed to embrace emerging technologies. Specific issues in IoT standardisation include interoperability, radio access, semantic interoperability, security 
Jouni K. Tervonen et al.

and privacy (Xu et al., 2014). Standards combining ISO/OSI and TCP/IP stacks are described and analysed by Palattella et al. (2013). In addition to standardisation bodies, various industrial alliances, such as the Industrial Internet Consortium (IIC), Open Interconnect Consortium and IPSO Alliance address interoperability issues and testing and provide reference architectures. The IIC's reference architecture addresses data engineering issues.

\subsection{Service design trends and issues}

As described in section 5, the service design field is expanding and evolving. The role of service design in the IoT context can be seen along a continuum of the further development of the service design field, where new methods are also needed in the evolution and development of new service innovations. Carlborg et al. (2014) conducted an extensive review tracing the evolution of service innovation research published from 1986 to 2010. According to these authors, the view has evolved from traditional product innovation 'to a multidimensional, all-encompassing notion that entails several functions, both within and outside the firm' (Carlborg et al., 2014). Over time, the focus has shifted from involving the customer to forming the organisation and then to a multidimensional phase focused on more diverse links between service innovation and business strategies (Carlborg at al., 2014). With continued technological development, services and manufacturing will become more intertwined and drive more service growth and innovation (Carlborg et al., 2014). As described, particularly in the Kone case, the concept of service design has been extended to involve organisations' system-level development and innovation models. With an organisational and systemic-level approach supporting practical methods, service design can bring together business developers, engineers and designers to build new possibilities.

IoT is an emerging field in service design. The nomination of the Service Design Network (2017a) for the 2016 Service Design Award provides an example of this as the nomination was a case study of the IoT Service Kit by Futurice (Service Design Network, 2017b). This project was created to meet the need for 'co-creative means for exploring user-centric interactive scenarios' that merge physical and digital realities to design IoT services (Service Design Network, 2017b). The Method Kit provides tools to review technological frameworks and map the entire customer journey to an IoT service. This IoT Service Kit is an example of the service design approach, which can bring a new mind-set to developing business excellence.

\subsection{Business excellence trends and issues}

The IoT with smart and connected product will result in dramatic changes in both competition and companies as they must improve their business excellence. As manufacturing companies progressively recognise increasing competition, one solution to provide business excellence is the connected product life cycle (PLM) proposed by Goto et al. (2016). The PLM platform centrally controls and visualises product data and service information gathered from different smart things, which are utilised in business systems.

IoT systems require that companies build and support an entirely new technology infrastructure, which Porter and Heppelmann (2014) name the 'technology stack'. A stack consists of multiple layers, including new product hardware, embedded software, connectivity, a product cloud consisting of software running on remote servers, a suite of security tools, a gateway for external information sources and, last but not least, 


\section{Survey of business excellence}

integration with enterprise systems. This integration connects business intelligence methods and data mining approaches, as well as other technical layers of IoT systems.

Porter and Heppelmann (2015) proposed that a new era of lean is emerging. Data flowing to and from products will enable product use and activities across the value chain and product life cycle to be streamlined in many new ways. To describe the value created with data, including data handling and engineering, Porter and Heppelmann (2015) suggested the term 'data lake'. Data from IoT products generate insights that help businesses, customers and partners optimise overall performance. Deep insights can be drawn from the combination of simple analytics applied to individual products and their data, more sophisticated analytics applied to product information connected to the lake, and company data from external sources (Porter and Heppelmann, 2015).

\subsection{Research trends}

We believe that the role and impact of well-defined, well-designed inter-cognitive communication between human users and IoT applications, including integration with social networks, will continue to grow and become more challenging as the focus is shifting from technology- and connectivity-driven design to data and user-driven design. When data from sensors are collected into the IoT platform, the physical product or device can be connected to digital services. Data analytics is developed as part of IoT platforms. The ability to analyse data in different forms and from different sources is becoming a trend. It should be possible to analyse data obtained from different platforms and sources. It is essential is to visualise large data masses and incorporate the situation consciousness of the system and new information into business decisions.

The combination of service design and data analysis can be used to develop new intelligent products and systems. It brings a human-centred approach to system development. The target is to focus on customer experience. The objective is to produce new innovative services through co-creation with the end user. The future trend is to develop methods to incorporate the results of data analysis into the service design process. The objective is to meet the need to use the service design process to develop sustainable tools for innovation, such as the IoT platform.

Data analysis and mining are ways to enhance the autonomous or cognitive ability of the IoT. This enhanced smartness has two important drivers. The first is improving the performance of the IoT system itself through, for instance, development of context-aware IoT middleware solutions, the use of artificial-intelligence techniques to create intelligent things or smart objects, and the combination of IoT and cloud computing. Contextawareness computing techniques, such as IoT middleware, are proposed to allow connecting billions of sensors to the Internet without the need for people to process all the data. Future IoT systems should have 'self-configuration, self-optimisation, selfprotection, and self-healing' capabilities (Xu et al., 2014). This means that the potential of data engineering is utilised in smart objects themselves or other objects.

In practice, data engineering has the potential to filter out redundant data and decide what data or information needs to be uploaded to the system and is useful for applications in a broad region with limited resources. Another key research issue in the IoT is communication and collaboration with other things. If the objects have similar goals or requirements, clustering technologies can be used to place them in the same groups, so the objects can easily know which objects need and do not need the information they hold (Tsai et al., 2014a).

The second important driver of the enhanced cognitivity of IoT via data engineering is the potential to people. In other words, the IoT acts like a semi-automatic intelligent 
Jouni K. Tervonen et al.

system that can provide more accurate suggestions for customers and end users in industrial IoT cases. Consequently, there is strong interest in the use of social networking to enhance communications among different IoT things. Social networks have changed the behaviour of Internet users, prompting companies to modify their marketing strategies. Another important development is that user discussion forums will include more members and transmit information much faster. Digital social behaviour can be used to enhance the performance of the future IoT, and the social networks in the digital world will become much larger and more complex, so designing a high-performance IoT will become an important research issue (Tsai et al., 2014a).

\subsection{Summary}

In Table 3, we summarise the future trends and challenges and their requirements and the reasons why they are especially crucial to the industrial IoT, along with the sections in which these issues are discussed in detail.

\section{Conclusion}

Although both IoT solutions and data engineering within the IoT are still considered to be in their infancy, this survey reveals the richness and delicacy of the opportunities to exploit business excellence via knowledge gathering and service design. As the examples in sections 3 and 4 show, knowledge discovery in databases will be a key driver

Table 3 Summary of future trends and challenges

\begin{tabular}{|c|c|c|}
\hline Trend or challenge & Brief Description of the Causes and Requirements & Details in \\
\hline $\begin{array}{l}\text { Knowledge } \\
\text { discovery }\end{array}$ & $\begin{array}{l}\text { IoT-based big data enable the creation of } \\
\text { semiautomatic systems and require new ways of data } \\
\text { analysis, such as distributed, instead of centralised, CI } \\
\text { methods and the combination of data mining } \\
\text { technologies with iterative learning methods. }\end{array}$ & Section 6.1 \\
\hline Standardisation & $\begin{array}{l}\text { Several standardisation efforts are underway but are not } \\
\text { integrated in a comprehensive framework. }\end{array}$ & Section 6.2 \\
\hline Service design & $\begin{array}{l}\text { Traditional product innovation becomes more } \\
\text { intertwined and multidimensional, including various } \\
\text { functions within and outside companies. }\end{array}$ & Section 6.3 \\
\hline Business excellence & $\begin{array}{l}\text { IoT changes in competition and companies require an } \\
\text { entirely new technology infrastructure (the technology } \\
\text { stack), ushering in a new era of lean technologies and } \\
\text { connected product life cycles. }\end{array}$ & Section 6.4 \\
\hline Research trends & $\begin{array}{l}\text { The focus is shifting from technology- and } \\
\text { connectivity-driven design to data- and user-driven } \\
\text { design, which requires multidisciplinary approaches } \\
\text { and increases the importance of inter-cognitive } \\
\text { communication and social networking. The growth role } \\
\text { of intra-cognitive communication allows for the } \\
\text { development of semiautomatic systems consisting } \\
\text { smart objects and enabling communication and } \\
\text { collaboration among different objects. }\end{array}$ & Section 6.5 \\
\hline
\end{tabular}




\section{Survey of business excellence}

reshaping current business models and generating new business opportunities in future IoT applications. The data engineering enhanced performance of devices gives them basic autonomous or cognitive capability. The combination of data engineering and iterative learning methods is one possible way to enhance IoT, so the system may learn incrementally and even interact with people. The combination of artificial cognitive objects and human capabilities will lead to the effective augmentation of humans.

The smart objects of IoT applications are expected to transform both competition between companies and enterprises or organisations themselves. Due to this paradigm change, business excellence will be essential as the IoT era unfolds. The creation of business excellence through service design is evident in the examples discussed in the section 5. Furthermore, we believe that in the future, it will become a prerequisite that business excellence methods and tools are either developed parallel to and interact with data engineering processes or are fully integrated into them. The examples discussed in sections $3-5$ can be utilised by companies and researchers as they show what and how methods of knowledge gathering and business excellence have been used in industrialIoT-based product, service or process innovation.

Our future research will continue to utilise and demonstrate the possibilities of data analysis and service design. The focus will be on small and medium size enterprises capability to adopt WSNs and IoT systems and to utilisation data in their operations. Another target of the future work is to apply data analysis and service design to education. Changes in work life demand new skills, and multi-professional, multi-cultural work environments create a need for communication skills. Understanding technological possibilities is important for professionals in all domains, but technology developers especially need to understand the usage context. Service modelling gives the technology developer knowledge of customer needs and end user experiences and returns feedback before even a single row of software code is developed. The future plan is to arrange workshops to develop a blood pressure analysis system for healthcare professionals. The goal is to recruit a heterogeneous team of students and professionals from different nationalities as well as domains (e.g. marketing, IT and health care). This working method will bring a broad view to application development and teach students new working methods.

\section{References}

Atzori, L., Iera, A. and Morabito, G. (2010) 'The Internet of Things: a survey', Computer Networks, Vol. 54 No. 15, pp.2787-2805.

Atzori, L., Iera, A., Morabito, G. and Nitti, M. (2012) 'The Social Internet of Things (SIoT) — when social networks meet the internet of things: concept, architecture and network characterization', Computer Networks, Vol. 56 No. 16, pp.3594-3608.

Baranyi, P. and Csapó, A. (2012) 'Definition and synergies of cognitive infocommunications', Acta Polytechnica Hungarica, Vol. 9 No. 1, pp.67-83.

Bello, P. (2017) 'What happens before service design?', in Miettinen S. (Ed.), An Introduction to Industrial Service Design, Routledge, New York, pp.110-116.

Bin, S., Yuan, L. and Xiaoyi, W. (2010), 'Research on data mining models for the internet of things', in 2010 International Conference on Image Analysis and Signal Processing, IEEE; Zhejiang, China, pp.127-132.

Boothe, W. and Lindberg, S. (2014) Handbook to Achieve Operational Excellence: A Realistic Guide Including All the Tools Needed, Reliabilityweb.com, Myers, Florida. 
Jouni K. Tervonen et al.

Cantoni, V., Lombardi, L. and Lombardi, P. (2006) 'Challenges for data mining in distributed sensor networks', in Proceedings of International Conference on Pattern Recognition, IEEE; Hong Kong, China, pp.1000-1007.

Carballido, J.A., Ponzoni, I. and Brignole, N.B. (2007) 'CGD-GA: a graph-based genetic algorithm for sensor network design', Information Sciences, Vol. 177 No. 22, pp.5091-5102.

Carlborg, P., Kindström, D. and Kowalkowski, C. (2014) 'The evolution of service innovation research: a critical review and synthesis', Service Industries Journal, Vol. 34 No. 5, pp.373398.

Creswell, J.W. and Plano Clark, V.L. (2011) Designing and Conducting Mixed Methods Research $2^{\text {nd }}$ ed., Sage: Los Angeles.

Domínguez, E., Pérez, B., Rubio, Á.L., Zapata, M.A., Lavilla, J. and Allué, A. (2014) ‘Occurrenceoriented design strategy for developing business process monitoring systems', IEEE Transactions on Knowledge and Data Engineering, Vol. 26 No. 7, pp.1749-1762.

Fayyad, U., Piatetsky-Shapiro, G. and Smyth, P. (1996) 'From data mining to knowledge discovery in databases', AI Magazine, Vol 17 No. 3, pp.37-53.

Förster, A. and Murphy, A.L. (2007). 'FROMS: feedback routing for optimizing multiple sinks in WSN with reinforcement learning', in International Conference on Intelligent Sensors, Sensor Networks and Information Processing, ISSNIP, IEEE; Melbourne, Australia, pp.371-376.

Förster, A. and Murphy, A.L. (2011) 'FROMS: a failure tolerant and mobility enabled multicast routing paradigm with reinforcement learning for WSNs', Ad Hoc Networks, Vol. 9 No. 5, pp.940-965.

Ghiasi, S., Srivastava, A., Yang, X. and Sarrafzadeh, M. (2002) 'Optimal energy aware clustering in sensor network', Sensors, Vol. 2 No. 7, pp.258-269.

Goto, S., Yoshie, O. and Fujimura, S. (2016) 'Internet of Things value for mechanical engineers and evolving commercial product lifecycle management system', in Proceedings of the IEEE International Conference on Industrial Engineering and Engineering Management, IEEE, Bali, Indonesia, pp.1021-1024.

Guillemin, P., Friess, P., Vermesan, O., Harrison, M., Vogt, H., Tomasella, M., Wouters, K., Gusmeroli, S. and Haller, S. (2009) Internet of Things: Strategic Research Roadmap, CERPIoT-Cluster of European Research Projects on the Internet of Things. Brussels, Belgium.

Heinzelman, W.B., Chandrakasan, A.P. and Balakrishnan, H. (2002) 'An application-specific protocol architecture for wireless microsensor networks', IEEE Transactions on Wireless Communications, Vol. 1 No. 4, pp.660-670.

Horvitz, E., Apacible, J., Sarin, R. and Liao, L. (2005) 'Prediction, expectation, and surprise: methods, designs, and study of a deployed traffic forecasting service', in 21st Conference on Uncertainty in Artificial Intelligence, UAI 2005, The Association for Uncertainty in Artificial Intelligence, Edinburgh, United Kingdom, pp.275-284.

$\mathrm{Hu}$, J., Song, J., Kang, X. and Zhang, M. (2006) 'A study of particle swarm optimization in urban traffic surveillance system', in IMACS Multiconference on 'Computational Engineering in Systems Applications', IEEE, Beijing, China, pp.2056-2061.

Isoherranen, V. and Kess, P. (2011) 'Analysis of strategy by strategy typology and orientation framework', Modern Economy, Vol. 2 No. 4, pp.575-583.

Isoherranen, V., Niinikoski, E., Malinen, T., Jokinen, M., Kess, P. and Kärkkäinen, M.K. (2016) 'Operational excellence evaluation model for SMEs and regional findings', in Proceedings of the IEEE International Conference on Industrial Engineering and Engineering Management, IEEE; Bali, Indonesia, pp.199-203.

Janssen, M.J. and den Hertog, P. (2016) 'Developing service-based business models: which innovation capability for which innovation dimension?', in Toivonen M. (Ed.), Service Innovation: Novel Ways of Creating Value in Actor Systems, Springer Japan, pp.97-128. 


\section{Survey of business excellence}

Kimbell, L. (2010) 'Marketing: connecting with people, creating value', in Stickdorn, M. and Schneider, J. (Eds.) This is Service Design Thinking: Basics, Tools, Cases, BIS Publishers, Amsterdam, pp.46-51.

Kulkarni, R.V., Förster, A. and Venayagamoorthy, G.K. (2011) 'Computational intelligence in wireless sensor networks: a survey', IEEE Communications Surveys and Tutorials, Vol. 13 No. 1, pp.68-96.

Lazzerini, B., Marcelloni, F., Vecchio, M., Croce, S. and Monaldi, E. (2006) 'A fuzzy approach to data aggregation to reduce power consumption in wireless sensor networks', in Annual Meeting of the North American Fuzzy Information Processing Society, IEEE; Montreal, Canada, pp.457-462.

Li, S., Xu, L.D. and Zhao, S. (2015) 'The Internet of Things: a survey', Information Systems Frontiers, Vol. 17 No. 2, pp.243-259.

Li, X., Liu, J., Sheng, Q.Z., Zeadally, S. and Zhong, W. (2011) 'TMS-RFID: temporal management of large-scale RFID applications', Information Systems Frontiers, Vol. 13 No. 4, pp.481-500.

Nitti, M., Girau, R. and Atzori, L. (2014) 'Trustworthiness management in the Social Internet of Things,' IEEE Transactions on Knowledge and Data Engineering, Vol. 26 No. 5, pp.12531266.

Ojasalo, K. (2017) 'Designing a service-dominant business model in the industrial context', in Miettinen, S. (Ed.), An introduction to industrial service design, Routledge, New York, pp.117-123.

Palattella, M.R., Accettura, N., Vilajosana, X., Watteyne, T., Grieco, L.A., Boggia, G., et al. (2013) 'Standardized protocol stack for the Internet of (important) Things', IEEE Communications Surveys and Tutorials, Vol. 15 No. 3, pp.1389-1406.

Perera, C., Zaslavsky, A., Christen, P. and Georgakopoulos, D. (2014) 'Context aware computing for the Internet of Things: a survey', IEEE Communications Surveys and Tutorials, Vol. 16 No. 1, pp.414-454.

Perera, K. and Dias, D. (2011) 'An intelligent driver guidance tool using location based services', in 2011 IEEE International Conference on Spatial Data Mining and Geographical Knowledge Services, ICSDM 2011-in Conjunction with $8^{\text {th }}$ Beijing International Workshop on Geographical Information Science, BJ-IWGIS 2011, IEEE, Fuzhou, China, pp.246-251.

Porter, M.E. and Heppelmann, J.E. (2014) 'How smart, connected products are transforming competition’, Harvard Business Review, Vol. 92 November 2014, pp.64-88.

Porter, M.E. and Heppelmann, J.E. (2015) 'How smart, connected products are transforming companies', Harvard Business Review, Vol. 93 October 2015, pp.96-112.

Rashidi, P. and Cook, D.J. (2010) 'An adaptive sensor mining framework for pervasive computing applications', Lecture Notes in Computer Science, Vol. 5840, pp.154-174.

Rashidi, P., Cook, D.J., Holder, L.B. and Schmitter-Edgecombe, M. (2011) 'Discovering activities to recognize and track in a smart environment', IEEE Transactions on Knowledge and Data Engineering, Vol. 23 No. 4, pp.527-539.

Sallai, G. (2012. 'The cradle of the cognitive infocommunications', Acta Polytechnica Hungarica, Vol. 9, No. 1, pp.171-181.

Sangiorgi, D. (2012) 'Value co-creation in design for services', in Miettinen, S. and Valtonen, A. (Eds.), Service Design with Theory: Discussions on Change, Value and Methods (Lapland University Press, Rovaniemi, pp.95-104.

Schleicher, J.M., Vögler, M., Dustdar, S. and Inzinger, C. (2016) 'Enabling a smart city application ecosystem: requirements and architectural aspects', IEEE Internet Computing, Vol. 20 No. 2, pp.58-65. 
Jouni K. Tervonen et al.

Service Design Network (2017a) About service design network. https://www.service-designnetwork.org/ (Accessed 18 January 2017).

Service Design Network (2017b) About Futurice GmbH: the IoT Service Kit. https://www.servicedesign-network.org/case-studies/iot-service-kit-futurice-gmbh (Accessed 18 January 2017).

Somasundaram, S., Khandavilli, A.P. and Sampalli, S. (2010) 'An intelligent RFID system for consumer businesses', in IEEE/ACM International Conference on Green Computing and Communications, GreenCom 2010, IEEE, Hangzhou, China, pp.539-545.

Sudhaakar, R., Sanzgiri, A., Demirbas, M. and Qiao, C. (2009) 'A plant-and-play wireless sensor network system for gate monitoring', in IEEE International Symposium on a World of Wireless, Mobile and Multimedia Networks and Workshops, WOWMOM 2009, IEEE; Kos, Greece, pp.19.

Tervonen, J., Isoherranen, V. and Heikkilä, M. (2015) 'A review of the cognitive capabilities and data analysis issues of the future industrial Internet-of-Things,' in IEEE International Conference on Cognitive Infocommunications (CogInfoCom 2015), IEEE, Györ, Hungary, pp.127-132.

Tervonen, J., Mikhaylov, K., Pieskä, S., Jämsä, J. and Heikkilä, M. (2014) 'Cognitive internet-ofthings solutions enabled by wireless sensor and actuator networks', in IEEE Conference on Cognitive Infocommunications (CogInfoCom 2014), IEEE, Vietri sul Mare, Italy, pp.97-102.

Tien, J.M. (2017) 'The sputnik of servgoods: autonomous vehicles', Journal of Systems Science and Systems Engineering, Vol. 26 No. 2, pp.133-162.

TomTom International BV (2016a) About TomTom city. https://www.tomtom.com/en_gb/trafficnews/about(Accessed 28 November 2016).

TomTom International BV (2016b) TomTom innovation future-proof. https://www.tomtom.com/en_gb/sat-nav/car-sat-nav/innovation/ (Accessed 28 November 2016).

Tsai, C., Lai, C., Chiang, M. and Yang, L.T. (2014a) 'Data mining for Internet of Things: a survey', IEEE Communications Surveys and Tutorials, Vol. 16 No. 1, pp.77-97.

Tsai, C., Lai, C. and Vasilakos, A.V. (2014b) 'Future Internet of Things: open issues and challenges', Wireless Networks, Vol. 20 No. 8, pp.2201-2217.

$\mathrm{Xu}, \mathrm{L} . \mathrm{D} ., \mathrm{He}, \mathrm{W}$. and Li, S. (2014) 'Internet of Things in industries: a survey', IEEE Transactions on Industrial Informatics, Vol. 10 No. 4, pp.2233-2243.

Younis, O. and Fahmy, S. (2004) 'HEED: a hybrid, energy-efficient, distributed clustering approach for ad hoc sensor networks', IEEE Transactions on Mobile Computing, Vol. 3 No. 4, pp.366-379. 
Survey of business excellence

Figure 1 Model of knowledge gathering

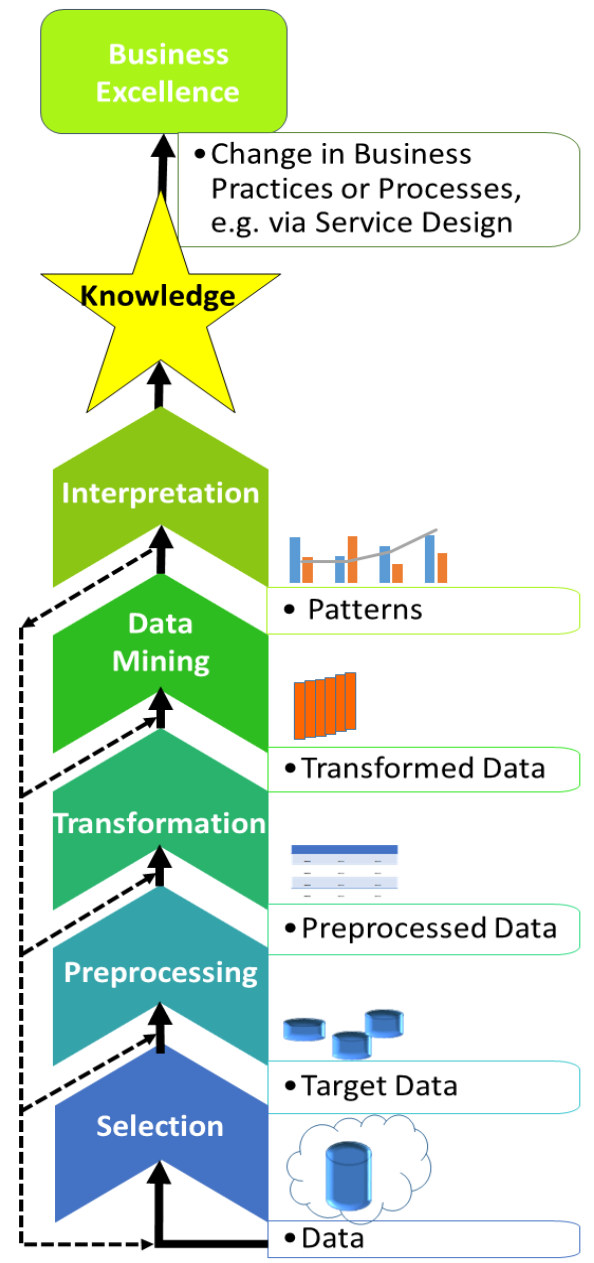

Source: Fayyad et al. (1996); Tsai et al. (2014a) 
Jouni K. Tervonen et al.

Table 1 Summary of computational intelligence experimental cases

\begin{tabular}{|c|c|c|c|c|c|}
\hline Example case & CI method & IoT challenge & $\begin{array}{c}\text { IoT } \\
\text { Domain }\end{array}$ & $\begin{array}{c}\text { Maturity leve } \\
\text { in model of } \\
\text { Goto et al. } \\
\text { (2016) }\end{array}$ & $\begin{array}{l}\text { CogInfoCom } \\
\text { remark }\end{array}$ \\
\hline $\begin{array}{l}\text { CGD-GA } \\
\text { (Carballido et } \\
\text { al., 2007) }\end{array}$ & $\begin{array}{l}\text { Evolutionary } \\
\text { algorithm }\end{array}$ & $\begin{array}{l}\text { Design and } \\
\text { deployment of } \\
\text { WSN parts (type, } \\
\text { amount and } \\
\text { location of nodes) }\end{array}$ & $\begin{array}{l}\text { Industry: } \\
\text { process } \\
\text { automation }\end{array}$ & Level 1 & $\begin{array}{l}\text { Intra-cognitive } \\
\text { communication } \\
\text { between objects } \\
\text { (sensor nodes) }\end{array}$ \\
\hline $\begin{array}{l}\text { PSO-UTSS } \\
\text { (Hu et al., } \\
2006 \text { ) }\end{array}$ & $\begin{array}{l}\text { Swarm } \\
\text { intelligence }\end{array}$ & $\begin{array}{l}\text { Design and } \\
\text { deployment of } \\
\text { sensor network } \\
\text { (topology planning } \\
\text { for cameras as } \\
\text { sensors) }\end{array}$ & $\begin{array}{l}\text { Industry: } \\
\text { ITS }\end{array}$ & Level 1 & $\begin{array}{l}\text { Intra-cognitive } \\
\text { communication } \\
\text { between objects } \\
\text { (sensor nodes) }\end{array}$ \\
\hline $\begin{array}{l}\text { FROMS } \\
\text { (Förster and } \\
\text { Murphy, 2007; } \\
\text { Förster and } \\
\text { Murphy, 2011), }\end{array}$ & $\begin{array}{l}\text { Reinforcement } \\
\text { learning }\end{array}$ & $\begin{array}{l}\text { Q-learning for the } \\
\text { energy efficient } \\
\text { routing of WSNs }\end{array}$ & $\begin{array}{l}\text { Not } \\
\text { specified } \\
\text { (testbed) }\end{array}$ & Level 1 & $\begin{array}{l}\text { Intra-cognitive } \\
\text { communication } \\
\text { between objects } \\
\text { (sensor nodes) }\end{array}$ \\
\hline $\begin{array}{l}\text { Data } \\
\text { aggregation } \\
\text { (Lazzerini et } \\
\text { al., 2006) }\end{array}$ & Fuzzy logic & $\begin{array}{l}\text { Flooding-based } \\
\text { data aggregation } \\
\text { to reduce power } \\
\text { consumption of } \\
\text { WSNs }\end{array}$ & $\begin{array}{l}\text { Society and } \\
\text { industry }\end{array}$ & Level 1 & $\begin{array}{l}\text { Intra-cognitive } \\
\text { communication } \\
\text { between objects } \\
\text { (sensor nodes) }\end{array}$ \\
\hline
\end{tabular}

Notes: The IoT domain of reinforcement learning is not specified, but the design is inspired by the environment domain and is well suited for the industry domain (e.g. process automation).

The maturity levels are: Level 0: As Is; Level 1: Improvement;

Level 2: Reforming; and Level 3: Transformation. 
Survey of business excellence

Table 2 Summary of data mining cases in the industry domain

\begin{tabular}{|c|c|c|c|c|c|}
\hline Example case & $\begin{array}{l}\text { Data mining } \\
\text { method }\end{array}$ & IoT challenge & IoT domain & $\begin{array}{c}\text { Maturity level } \\
\text { in model of } \\
\text { Goto et al. } \\
\text { (2016) }\end{array}$ & $\begin{array}{l}\text { CogInfoCom } \\
\text { remark }\end{array}$ \\
\hline $\begin{array}{l}\text { Routing } \\
\text { algorithms }\end{array}$ & Clustering & $\begin{array}{l}\text { Efficient } \\
\text { routing } \\
\text { protocol for } \\
\text { WSNs }\end{array}$ & $\begin{array}{l}\text { Industry, } \\
\text { environment, } \\
\text { society }\end{array}$ & Level 1 & $\begin{array}{l}\text { Intra-cognitive } \\
\text { communication } \\
\text { between objects } \\
\text { (sensor nodes) }\end{array}$ \\
\hline $\begin{array}{l}\text { Traffic forecast } \\
\text { (Horvitz et al., } \\
\text { 2005) }\end{array}$ & Classification & $\begin{array}{l}\text { ITS traffic } \\
\text { forecast for } \\
\text { congestion } \\
\text { avoidance }\end{array}$ & $\begin{array}{l}\text { Industry: } \\
\text { ITS }\end{array}$ & Level 2 & $\begin{array}{l}\text { Several intra- } \\
\text { cognitive and } \\
\text { two inter- } \\
\text { cognitive } \\
\text { communication } \\
\text { links }\end{array}$ \\
\hline $\begin{array}{l}\text { Driver guidance } \\
\text { (Perera and } \\
\text { Dias, 2011) }\end{array}$ & Classification & $\begin{array}{l}\text { ITS intelligent } \\
\text { driver- } \\
\text { guidance tool } \\
\text { for congestion } \\
\text { avoidance }\end{array}$ & $\begin{array}{l}\text { Industry: } \\
\text { ITS }\end{array}$ & Level 2 & $\begin{array}{l}\text { Intra- and inter- } \\
\text { cognitive } \\
\text { communication }\end{array}$ \\
\hline $\begin{array}{l}\text { Gate monitoring } \\
\text { (Sudhaakar et al., } \\
\text { 2009) }\end{array}$ & Classification & $\begin{array}{l}\text { WSN-based } \\
\text { car-parking } \\
\text { aid }\end{array}$ & $\begin{array}{l}\text { Industry: } \\
\text { logistics } \\
\text { and } \\
\text { transport }\end{array}$ & Level 2 & $\begin{array}{l}\text { Intra- and inter- } \\
\text { cognitive } \\
\text { communication }\end{array}$ \\
\hline $\begin{array}{l}\text { TMS-RFID } \\
\text { (Li et al., 2011) }\end{array}$ & $\begin{array}{l}\text { Frequent } \\
\text { pattern } \\
\text { mining }\end{array}$ & $\begin{array}{l}\text { Temporal } \\
\text { management } \\
\text { of large-scale } \\
\text { RFID } \\
\text { applications }\end{array}$ & $\begin{array}{l}\text { Industry, } \\
\text { environment, } \\
\text { society }\end{array}$ & Level 1 & $\begin{array}{l}\text { Intra-cognitive } \\
\text { communication } \\
\text { between objects } \\
\text { (readers, tags } \\
\text { and databases) }\end{array}$ \\
\hline $\begin{array}{l}\text { Intelligent RFID } \\
\text { (Somasundaram } \\
\text { et al., 2010) }\end{array}$ & $\begin{array}{l}\text { Frequent } \\
\text { pattern } \\
\text { mining }\end{array}$ & $\begin{array}{l}\text { Customer } \\
\text { satisfaction } \\
\text { and guidance } \\
\text { in shops }\end{array}$ & $\begin{array}{l}\text { Industry: } \\
\text { logistics }\end{array}$ & Level 3 & $\begin{array}{l}\text { Intra- and inter- } \\
\text { cognitive } \\
\text { communication }\end{array}$ \\
\hline
\end{tabular}

Notes: $\quad$ There are several examples of routing algorithms for energy-efficient protocols for WSNs (Ghiasi et al., 2002; Heinzelman et al., 2002; Younis and Fahmy, 2004).

Maturity levels are: Level 0: As is; Level 1: Improvement;

Level 2: Reforming; Level 3: Transformation. 
Jouni K. Tervonen et al.

Figure 2 Outline of parallel knowledge discovery and service design

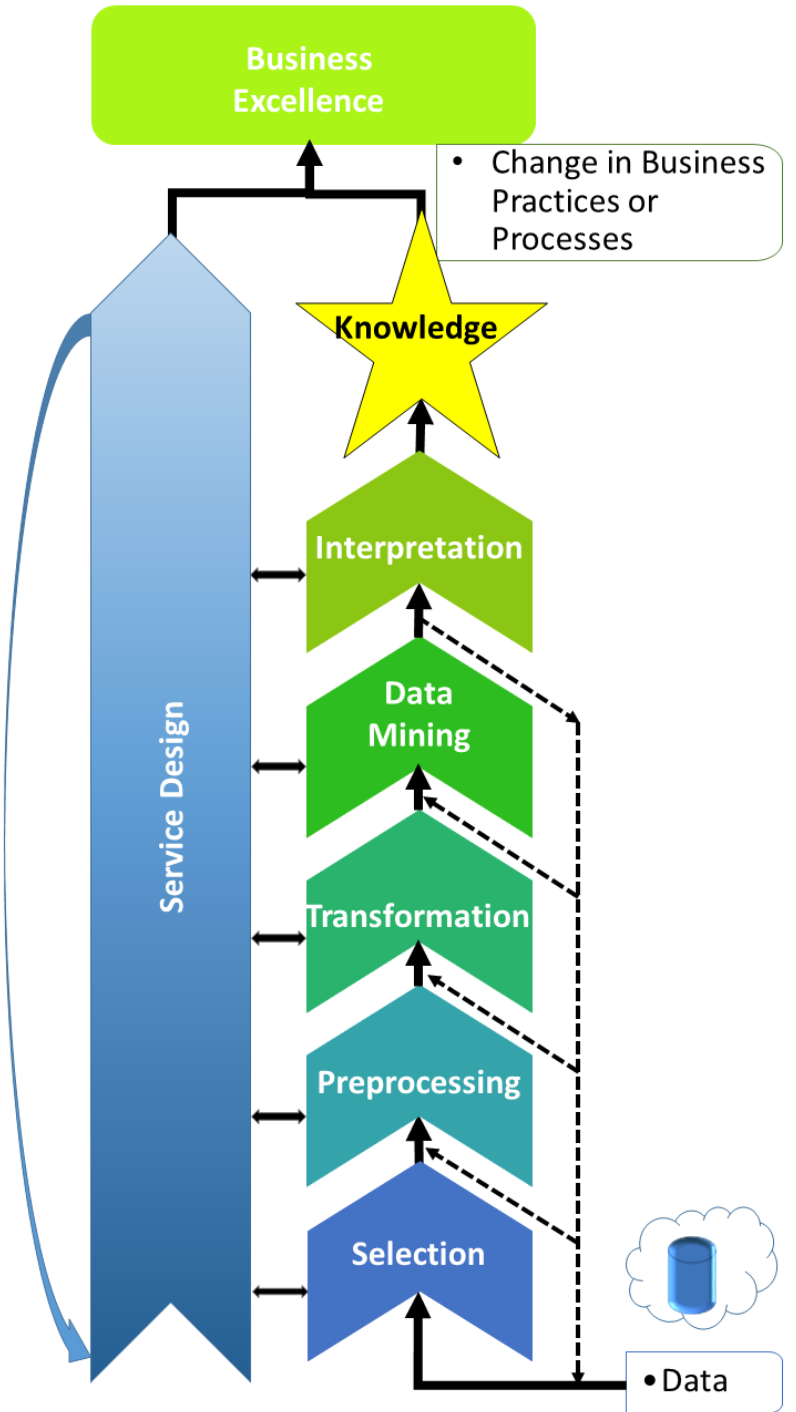


Survey of business excellence

Table 3 Summary of future trends and challenges

\begin{tabular}{|c|c|c|}
\hline Trend or challenge & Brief Description of the Causes and Requirements & Details in \\
\hline $\begin{array}{l}\text { Knowledge } \\
\text { discovery }\end{array}$ & $\begin{array}{l}\text { IoT-based big data enable the creation of } \\
\text { semiautomatic systems and require new ways of data } \\
\text { analysis, such as distributed, instead of centralised, CI } \\
\text { methods and the combination of data mining } \\
\text { technologies with iterative learning methods. }\end{array}$ & Section 6.1 \\
\hline Standardisation & $\begin{array}{l}\text { Several standardisation efforts are underway but are not } \\
\text { integrated in a comprehensive framework. }\end{array}$ & Section 6.2 \\
\hline Service design & $\begin{array}{l}\text { Traditional product innovation becomes more } \\
\text { intertwined and multidimensional, including various } \\
\text { functions within and outside companies. }\end{array}$ & Section 6.3 \\
\hline Business excellence & $\begin{array}{l}\text { IoT changes in competition and companies require an } \\
\text { entirely new technology infrastructure (the technology } \\
\text { stack), ushering in a new era of lean technologies and } \\
\text { connected product life cycles. }\end{array}$ & Section 6.4 \\
\hline Research trends & $\begin{array}{l}\text { The focus is shifting from technology- and } \\
\text { connectivity-driven design to data- and user-driven } \\
\text { design, which requires multidisciplinary approaches } \\
\text { and increases the importance of inter-cognitive } \\
\text { communication and social networking. The growth role } \\
\text { of intra-cognitive communication allows for the } \\
\text { development of semiautomatic systems consisting } \\
\text { smart objects and enabling communication and } \\
\text { collaboration among different objects. }\end{array}$ & Section 6.5 \\
\hline
\end{tabular}

